\title{
Heavy Metal Adsorption by Montmorillonites Modified with Natural Organic Cations
}

\author{
M. Cruz-Guzmán, R. Celis, M. C. Hermosín, W. C. Koskinen, E. A. Nater, and J. Cornejo*
}

\begin{abstract}
Agricultural and industrial pollution release large amounts of heavy metals into the atmosphere, surface water, soil, and plants. The protection and restoration of soils and water contaminated with heavy metals generate a great need to develop efficient adsorbents for these pollutants. This study reports the adsorption of $\mathrm{Pb}(\mathrm{II})$ and $\mathrm{Hg}$ (II) by two reference montmorillonites, Wyoming (SWy-2) and Arizona (SAz-1), that were pretreated with various natural organic cations containing different functional groups (L-carnitine, L-cysteine ethyl ester, L-cystine dimethyl ester, and thiamine cations) and with synthetic, nonfunctionalized organic cations (hexadecyltrimethylammonium [HDTMA] and phenyltrimethylammonium [PTMA] cations). Most of the organoclays adsorbed less $\mathrm{Pb}$ (II) than the untreated montmorillonites, with the exception of the L-carnitinetreated montmorillonites. The carboxyl functional group on Lcarnitine was apparently effective for complexing $\mathrm{Pb}$. In contrast, $\mathrm{Hg}$ (II) adsorption was greatly increased by several of the organic cation pretreatments. Sulfur-containing organic functional groups enhanced $\mathrm{Hg}$ (II) adsorption. The synthetic organic cations PTMA and HDTMA suppressed adsorption of $\mathrm{Pb}$ (II) and $\mathrm{Hg}$ (II) because these organic cations competed with the metals for adsorption sites on the clay surfaces and lack organic functional groups capable of interacting with the heavy metals. These findings are consistent with prior understanding of organic functional group-metal complexation reactions but go further by demonstrating that organoclays can be selectively functionalized with natural organic cations to enhance their affinity for heavy metals.
\end{abstract}

$\mathrm{H}$ EAVY METALS are important environmental pollutants threatening the health of human populations and natural ecosystems. Metals contamination is a persistent problem in many contaminated soils. The most commonly occurring metals are $\mathrm{Cd}, \mathrm{Cu}, \mathrm{Ni}, \mathrm{Pb}, \mathrm{Cr}, \mathrm{Zn}$, and $\mathrm{Hg}$ (Tiller, 1989). The presence of metals in groundwater can also pose a significant threat to human health and ecological systems.

Different techniques have been proposed in the literature for the remediation of soils and water contaminated by heavy metals. General approaches to remediation of metal contamination include isolation, immobilization, toxicity reduction, physical separation, and extraction (Evanko and Dzombak, 1997). For the immobilization and separation of metal species by adsorptive techniques, the use of clay minerals has been extensively studied because of their high specific surface area, cation exchange capacity, and adsorption capacity

M. Cruz-Guzmán, R. Celis, M.C. Hermosín, and J. Cornejo, Instituto de Recursos Naturales y Agrobiología de Sevilla, CSIC, P.O. Box 1052, 41080 Sevilla, Spain; W.C. Koskinen and E.A. Nater, USDAARS, 1991 Upper Buford Circle, Rm. 439, St. Paul, MN 55108. Received 26 Apr. 2005. *Corresponding author (cornejo@irnase. csic.es).

Published in Soil Sci. Soc. Am. J. 70:215-221 (2006).

Soil Chemistry

doi:10.2136/sssaj2005.0131

(c) Soil Science Society of America

677 S. Segoe Rd., Madison, WI 53711 USA
(Stadler and Schindler, 1993; Siantar et al., 1994; Brigatti et al., 1996; Undabeytia et al., 1996; Staunton and Roubaud, 1997).

The reactions with reagents containing metal-chelating functionalities have recently been explored in an effort to enhance the heavy metal binding capacities of clay minerals and their selectivity to the type of metal (Mercier and Detellier, 1995; Mercier and Pinnavaia, 1998; Celis et al., 2000). For instance, covalent grafting of ligands containing the thiol (-SH) functionality has been shown to improve the loading capacities and affinities of clay minerals for $\mathrm{Hg}$ (II) ions (Mercier and Detellier, 1995; Celis et al., 2000). A suitable selection of the functionalization mechanism to avoid clogging of the limited pore space of the clay mineral after functionalization has been stressed as important in improving the performance of functionalized clay minerals as adsorbents of heavy metals (Celis et al., 2000).

Organoclays (i.e., natural clay minerals with their original inorganic exchangeable cations replaced with organic cations) have been shown to be excellent adsorbents for different kinds of organic molecules. Accordingly, they have been proposed for decontamination of soils and water contaminated with organic pollutants (Hermosín and Cornejo, 1992; Celis et al., 1999; Carrizosa et al., 2001; Andrades et al., 2004). In contrast, organoclays have received limited interest as adsorbents of heavy metals, primarily because the organic cations most commonly used for their synthesis have been synthetic alkylammonium-type cations, which compete with metals for adsorption sites on the clay mineral surfaces and lack organic functional groups capable of interacting with heavy metals (Lee et al., 2002). Recent studies have shown that the presence of certain functionalities $(-\mathrm{COOH},-\mathrm{SH})$ in the alkylammonium cation can provide the resulting organoclays with affinity for heavy metal ions (Sheng et al., 1999; Celis et al., 2000). Nevertheless, there is little prior work on how the presence of different functionalities influences the heavy metal adsorption capacity of organoclays.

The present work was designed to provide further insight into the heavy metal adsorption capacity of functionalized organoclays. The adsorption-desorption of $\mathrm{Pb}$ (II) and $\mathrm{Hg}(\mathrm{II})$ ions by two reference montmorillonites pretreated with four natural, functionalized organic cations (L-carnitine, L-cysteine ethyl ester, L-cystine dimethylester, and thiamine) was determined and compared with the adsorption behavior of organoclays prepared from classical alkylammonium cations without specific functional groups (phenyltrimethylammonium

Abbreviations: AAS, atomic absorption spectroscopy; CAR, Lcarnitine; CEC, cation exchange capacity; CYSTE, L-cysteine ethyl ester; CYSTI, L-cystine dimethyl ester; HDTMA, hexadecyltrimethylammonium; PTMA, phenyltrimethylammonium; SA, Arizona montmorillonite; SW, Wyoming montmorillonite; THIAM, thiamine. 
[PTMA] and hexadecyltrimethylammonium [HDTMA]). In a previous paper, we reported that the presence of polar functionalities in the structure of several natural organic cations greatly influenced the capacity and selectivity of organoclays in adsorbing pesticides containing diverse polar functional groups (Cruz-Guzmán et al., 2005). Here, we assess how the presence of these organic functionalities in the organic cations influences the affinity of the resulting organoclays for heavy metal ions.

\section{MATERIALS AND METHODS \\ Organic Cations and Heavy Metals}

The four natural organic cations, L-carnitine, L-cysteine ethyl ester, L-cystine dimethyl ester, and thiamine (purity $>98 \%$ ) and the synthetic alkylammonium organic cations, PTMA and HDTMA, were purchased as high-purity chloride salts from Sigma (Germany). The chemical structures of the organic cations used are shown in Fig. 1. High-purity $\mathrm{Pb}\left(\mathrm{NO}_{3}\right)_{2}$ and $\mathrm{Hg}\left(\mathrm{NO}_{3}\right)_{2}$ (purity $=99 \%$ ) were supplied by Sigma, ACS reagent. Initial heavy metal solutions were prepared in 0.001 $M \mathrm{HNO}_{3}(\mathrm{pH} 3)$ to avoid precipitation and to simulate a worstcase scenario of heavy metal mobilization.

\section{Synthesis of the Organoclays}

SWy-2 Wyoming montmorillonite (SW) and SAz-1 Arizona montmorillonite (SA) from The Clay Minerals Society (Columbia, MO) were exchanged with the four natural organic cations through ion exchange reactions (Cruz-Guzmán et al., 2004). For the synthesis, the amount of L-carnitine, L-cysteine ethyl ester, L-cystine dimethyl ester, or thiamine (chloride salts) corresponding to $50 \%, 100 \%$, or $150 \%$ of the cation exchange capacity of SW $\left(\mathrm{CEC}_{\mathrm{SW}}=764 \mathrm{mmol} \mathrm{kg}^{-1}\right)$ and SA $\left(\mathrm{CEC}_{\mathrm{SA}}=1200 \mathrm{mmol} \mathrm{kg}{ }^{-1}\right)$ were dissolved in $50 \mathrm{~mL}$ of $1 \mathrm{mM}$ $\mathrm{HNO}_{3}$ and added to $1 \mathrm{~g}$ of each type of montmorillonite.

$$
\text { L-cysteine ethyl ester (CYSTE) }
$$

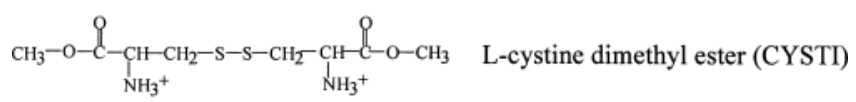<smiles></smiles>

Thiamine (THIAM)

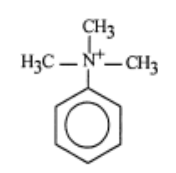

Phenyltrimethylammonium (PTMA)

$$
\mathrm{H}_{3} \mathrm{C}-\left(\mathrm{CH}_{2}\right)_{15}-\stackrel{+}{\mathrm{N}}-\left(\mathrm{CH}_{3}\right)_{3}
$$

Hexadecyltrimethylammonium (HDTMA)

\begin{tabular}{|c|c|c|c|}
\hline \multirow[b]{2}{*}{ Sample } & \multirow[b]{2}{*}{ Organic cation } & \multicolumn{2}{|c|}{ OCtS $\dagger$} \\
\hline & & Theoretical & Actual \\
\hline & & $-\%$ & . \\
\hline SW & - & - & - \\
\hline SW-CAR ${ }_{100}$ & L-Carnitine & 100 & 43 \\
\hline SW-CAR R 150 & L-Carnitine & 150 & 72 \\
\hline SW-CYSTI & L-Cystine dimethyl ester & 50 & 42 \\
\hline SW-CYSTI & L-Cystine dimethyl ester & 100 & 93 \\
\hline SW-CYSTE $_{50}$ & L-Cysteine ethyl ester & $\mathbf{5 0}$ & 50 \\
\hline SW-CYSTE $_{100}$ & L-Cysteine ethyl ester & 100 & 83 \\
\hline SW-THIAM ${ }_{50}$ & Thiamine & $\mathbf{5 0}$ & 48 \\
\hline SW-THIAM & Thiamine & 100 & 98 \\
\hline SW-HDTMA & HDTMA & 50 & 55 \\
\hline SW-HDTMA 100 & HDTMA & 100 & 83 \\
\hline SW-PTMA ${ }_{50}$ & PTMA & 50 & 56 \\
\hline SW-PTMA 100 & PTMA & 100 & 85 \\
\hline SA & - & - & - \\
\hline $\mathbf{S A}-\mathbf{C A} \mathbf{R}_{50}$ & L-Carnitine & 50 & 23 \\
\hline SA-CAR $\mathbf{R}_{100}$ & L-Carnitine & 100 & 39 \\
\hline SA-CAR 150 & L-Carnitine & 150 & 48 \\
\hline SA-CYSTI & L-Cystine dimethyl ester & $\mathbf{5 0}$ & 54 \\
\hline SA-CYSTI 100 & L-Cystine dimethyl ester & 100 & 77 \\
\hline SA-CYSTE $_{50}$ & L-Cysteine ethyl ester & 50 & 22 \\
\hline SA-CYSTE & L-Cysteine ethyl ester & 100 & 32 \\
\hline SA-THIAM & Thiamine & $\mathbf{5 0}$ & 50 \\
\hline SA-THIAM & Thiamine & 100 & 84 \\
\hline SA-HDTMA $_{50}$ & HDTMA & 50 & 53 \\
\hline SA-HDTMA & HDTMA & 100 & 75 \\
\hline SA-PTMA $_{50}$ & PTMA & 50 & 54 \\
\hline SA-PTMA & PTMA & 100 & 83 \\
\hline
\end{tabular}

Fig. 1. Chemical structure of L-carnitine, L-cysteine ethyl ester, L-cystine dimethyl ester, thiamine, PTMA, and HDTMA cations.
Table 1. Nomenclature of the organoclays.

$\dagger$ Organic cation saturation: percentage of the CEC compensated by organic cations.

Acidic conditions were used to ensure the protonation of the biomolecules, thus favoring the exchange reaction.

The suspensions were shaken for $24 \mathrm{~h}$, centrifuged, washed three times with $100 \mathrm{~mL}$ of distilled water, and freeze-dried. Blank clay samples, SW(Blank) and SA(Blank), were prepared by shaking $1 \mathrm{~g}$ of clay in $50 \mathrm{~mL}$ of $1 \mathrm{~m} M \mathrm{HNO}_{3}$ for $24 \mathrm{~h}$, washing three times with $100 \mathrm{~mL}$ of distilled water, and freezedrying. These samples, free of organic cations, served as a control and helped evaluate the effects of the acid treatment on the clay mineral during the synthesis procedure.

The nomenclature of the different samples prepared in this work is summarized in Table 1. Methods for characterization of these organoclays have been reported previously (Cruz-Guzmán et al., 2004; 2005). The two alkylammonium-exchanged clays used as reference materials in the adsorption-desorption experiments were HDTMA- and PTMA-montmorillonite, containing an amount of alkylammonium cation equal to $50 \%$ and $100 \%$ of the CEC of SW and SA. The preparation and characteristics of these samples have been reported elsewhere (Celis et al., 2002).

\section{Heavy Metal Adsorption-Desorption Experiments}

$\mathrm{Pb}$ (II) and $\mathrm{Hg}(\mathrm{II})$ adsorption-desorption isotherms were obtained using the batch equilibration procedure. Duplicate 10 -mg adsorbent samples were equilibrated for $24 \mathrm{~h}$ at $20 \pm 2^{\circ} \mathrm{C}$ with $10 \mathrm{~mL}$ of aqueous solutions $(\mathrm{pH} 3)$ of $\mathrm{Pb}\left(\mathrm{NO}_{3}\right)_{2}$ or $\mathrm{Hg}\left(\mathrm{NO}_{3}\right)_{2}$ (Sigma, ACS reagent) with metal ion concentrations ranging from $0.2-1.5 \mathrm{mmol} \mathrm{L}^{-1}$. For all adsorbents, the $\mathrm{pH}$ of the suspensions remained $3.0 \pm 0.3$ after a 24 -h equilibration. After equilibration, the suspensions were centrifuged, and $5 \mathrm{~mL}$ of the supernatant solution was removed for analysis. The concentration of heavy metal in the supernatant was determined by atomic absorption spectroscopy (AAS) using a PerkinElmer 1100B atomic absorption spectrometer. The amount of metal adsorbed was calculated as the difference between the initial and final solution concentrations. Metal solutions without 
adsorbent were also shaken for $24 \mathrm{~h}$ and served as controls. For the experimental conditions used, the sensitivity of AAS for $\mathrm{Pb}$ (II) and $\mathrm{Hg}$ (II) analysis was about 0.002 and $0.025 \mathrm{mmol} \mathrm{L}^{-1}$, respectively. Due to the high concentrations used in the adsorption experiments (initial concentrations $\geq 0.25 \mathrm{mmol} \mathrm{L}^{-1}$ ), errors associated with metal analysis were generally $<10 \%$. The behavior of selected adsorbents at high $\mathrm{Hg}$ concentrations was confirmed at a lower concentration range $\left(0.01-0.1 \mathrm{mmol} \mathrm{L}^{-1}\right)$ by the use of the Cold Vapor Atomic Fluorescence Spectrometry (CVAS) technique, according to the method of Bloom and Crecelius (1983).

Desorption was measured immediately after adsorption

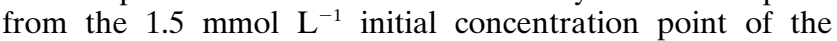
adsorption isotherms. The $5 \mathrm{~mL}$ of supernatant removed for the adsorption analysis were replaced with $5 \mathrm{~mL}$ of $\mathrm{HNO}_{3}$, $\mathrm{NaNO}_{3}$, or $\mathrm{Ca}\left(\mathrm{NO}_{3}\right)_{2}$ at different concentrations. The suspensions were shaken at $20 \pm 2^{\circ} \mathrm{C}$ for $24 \mathrm{~h}$ and centrifuged, and the metal concentration determined in the supernatant. This desorption procedure was repeated three times. All adsorption and desorption studies were conducted in duplicate.

Heavy metal adsorption isotherms were fit to the Langmuir equation: $\mathrm{C}_{\mathrm{e}} / \mathrm{C}_{\mathrm{s}}=\mathrm{C}_{\mathrm{e}} / \mathrm{C}_{\mathrm{m}}+1 / \mathrm{C}_{\mathrm{m}} \cdot \mathrm{L}$, where $\mathrm{C}_{\mathrm{s}}\left(\mathrm{mmol} \mathrm{kg}^{-1}\right)$ is the amount of heavy metal adsorbed at the equilibrium concentration $\mathrm{C}_{\mathrm{e}}\left(\mathrm{mmol} \mathrm{L}^{-1}\right), \mathrm{C}_{\mathrm{m}}\left(\mathrm{mmol} \mathrm{kg}{ }^{-1}\right)$ is the maximum adsorption capacity of the adsorbent, and $\mathrm{L}\left(\mathrm{L} \mathrm{mmol}^{-1}\right)$ is the Langmuir constant, which is related to the free energy of adsorption (Gu et al., 1995). $\mathrm{C}_{\mathrm{m}}$ and $\mathrm{L}$ can be calculated from the linear plot of $\mathrm{C}_{\mathrm{e}} / \mathrm{C}_{\mathrm{s}}$ versus $\mathrm{C}_{\mathrm{e}}$.

\section{RESULTS AND DISCUSSION $\mathrm{Pb}$ (II) and Hg(II) Adsorption Studies}

We fit the $\mathrm{Pb}$ (II) and $\mathrm{Hg}$ (II) adsorption isotherms to the Langmuir equation to obtain coefficients $\mathrm{C}_{\mathrm{m}}$ and $\mathrm{L}$ (Table 2). The adsorption coefficients for blank clay samples are not shown because they were similar to the values for the untreated clay samples. All adsorption isotherms, except $\mathrm{Pb}$ (II) on $\mathrm{SW}$-alkylammonium and SA-HDTMA samples and $\mathrm{Hg}(\mathrm{II})$ on SA-HDTMA samples, fit the Langmuir equation with $R^{2}>0.93$.

\section{Pb(II) Adsorption}

With the exception of SW-CAR, SA-CAR, and SACYSTE, the organoclays had lower adsorption coefficients, $\mathrm{K}_{\mathrm{d}}$ and $\mathrm{C}_{\mathrm{m}}$, as compared with the untreated clay minerals (Table 2). Therefore, replacement of the inorganic exchangeable cations by the organic cations produced, in most cases, a decrease in the adsorbent capacity of the montmorillonites for $\mathrm{Pb}$ (II), similar to the results obtained by Celis et al. (2000). Only the clays treated with CAR and SA treated with CYSTE had an adsorption behavior similar to that of the untreated clay mineral. For clay-CAR samples, although CAR occupies a $\mathrm{Pb}(\mathrm{II})$ retention site on the clay surface (i.e., a cation exchange site) it contains also a carboxylic functional group, for which $\mathrm{Pb}(\mathrm{II})$ has a high affinity (Table 2, Fig. 2). The higher $L$ Langmuir coefficients for the SW clays exchanged with CAR, as compared with values for the untreated clay, support the high affinity of $\mathrm{Pb}$ (II) for the carboxylic group of carnitine (Table 2).

For SA-CYSTE, the low amount of organic cation in the organoclay (22-32\%) (Table 1) could explain the high capacity of available active sites for the retention of $\mathrm{Pb}(\mathrm{II})$, similar to that in the original SA clay (Table 2). In addition, the -SH group of CYSTE could complex this metal (Tofan and Paduraru, 2004).

Table 2. $\mathrm{K}_{\mathrm{d}}$ and Langmuir coefficients for $\mathrm{Pb}(\mathrm{II})$ and $\mathrm{Hg}(\mathrm{II})$ adsorption on unexchanged and exchanged clays.

\begin{tabular}{|c|c|c|c|c|c|c|}
\hline \multirow[b]{2}{*}{$\underline{\text { Sample }}$} & \multicolumn{3}{|c|}{$\mathbf{P b}(\mathrm{II})$} & \multicolumn{3}{|c|}{ Hg(II) } \\
\hline & $\boldsymbol{K}_{\mathrm{d}}^{\dagger}$ & $\mathbf{C}_{\mathbf{m}} \neq$ & $\mathbf{L}$ & $\boldsymbol{K}_{\mathrm{d}}^{\dagger}$ & $\mathbf{C}_{\mathbf{m}} \div$ & $\mathbf{L}$ \\
\hline SW & $356 \pm 15 \S$ & $393(363-429) \S$ & $1(1-1)$ & $210 \pm 84$ & $294(265-331)$ & $3(2-4)$ \\
\hline SW-CAR ${ }_{100}$ & $\mathbf{3 2 7} \pm \mathbf{2 3}$ & 198 (175-228) & $9(6-38)$ & $1019 \pm 108$ & $402(362-452)$ & $4(3-6)$ \\
\hline SW-CAR ${ }_{150}$ & $274 \pm 6$ & $207(188-229)$ & 6 (4-9) & n.d. & $398(355-410)$ & $4(5-7)$ \\
\hline SW-CYSTI & $131 \pm 5$ & n.d.ग & n.d. & $2838 \pm 456$ & 738 (693-789) & $12(9-20)$ \\
\hline SW-CYSTI & $70 \pm 4$ & n.d. & n.d. & $\mathbf{1 3 8 9 3} \pm 5 \mathbf{5 1 7 6}$ & 805 (762-853) & $26(16-96)$ \\
\hline SW-CYSTE $_{50}$ & $82 \pm 10$ & n.d. & n.d. & $1511 \pm 76$ & $430(409-454)$ & $13(9-24)$ \\
\hline SW-CYSTE & $66 \pm 4$ & n.d. & n.d. & $862 \pm 45$ & $261(257-266)$ & $26(19-42)$ \\
\hline SW-THIAM & $153 \pm 7$ & n.d. & n.d. & $5194 \pm 1071$ & $372(359-387)$ & $67(22-84)$ \\
\hline SW-THIAM & $27 \pm 6$ & n.d. & n.d. & $1046 \pm 44$ & $248(239-258)$ & $44(19-55)$ \\
\hline SW-HDTMA & $217 \pm 35$ & $195(162-246)$ & $2(1-3)$ & $67 \pm 26$ & n.d. & n.d. \\
\hline SW-HDTMA & $67 \pm 22$ & 0\# & - & $19 \pm 6$ & n.d. & n.d. \\
\hline SW-PTMA $\mathbf{A}_{50}$ & $\mathbf{3 0 4} \pm \mathbf{1 7}$ & 241 (197-311) & $2(1-4)$ & $160 \pm 5$ & n.d. & n.d. \\
\hline SW-PTMA & $200 \pm 45$ & $136(101-207)$ & 3 (1-10) & $49 \pm 19$ & n.d. & n.d. \\
\hline SA & $930 \pm 0$ & $413(382-450)$ & $6(4-8)$ & $543 \pm 23$ & $339(319-360)$ & $3(2-4)$ \\
\hline $\mathbf{S A}-\mathbf{C A R}_{50}$ & $1190 \pm 22$ & $436(387-499)$ & $5(3-8)$ & $1108 \pm 90$ & 439 (411-470) & $5(4-7)$ \\
\hline $\mathbf{S A}-\mathbf{C A R} \mathbf{R}_{100}$ & $1161 \pm 7$ & 364 (354-374) & $8(7-9)$ & $1220 \pm 192$ & $473(443-508)$ & $6(5-8)$ \\
\hline SA-CAR 150 & $1242 \pm 45$ & $428(372-505)$ & $5(3-10)$ & $1560 \pm 148$ & 451 (411-499) & $8(5-16)$ \\
\hline SA-CYSTI $_{50}$ & $396 \pm 16$ & n.d. & n.d. & $23985 \pm 4997$ & 947 (894-1007) & $24(17-38)$ \\
\hline SA-CYSTI & $241 \pm 26$ & n.d. & n.d. & $39067 \pm 1908$ & 991 (957-1028) & $53(38-82)$ \\
\hline SA-CYSTE $_{50}$ & $831 \pm 156$ & n.d. & n.d. & $4998 \pm 86$ & 642 (604-686) & $16(11-28)$ \\
\hline SA-CYSTE & $1191 \pm 130$ & n.d. & n.d. & $41399 \pm 4240$ & 819 (770-874) & $35(21-91)$ \\
\hline SA-THIAM $_{50}$ & $346 \pm 3$ & n.d. & n.d. & $4254 \pm 197$ & $455(423-492)$ & $25(12-50)$ \\
\hline SA-THIAM ${ }_{100}$ & $62 \pm 26$ & n.d. & n.d. & $63961 \pm 4997$ & 574 (535-619) & $42(18-82)$ \\
\hline SA-HDTMA & $121 \pm 14$ & 96 (82-115) & $4(2-13)$ & $89 \pm 15$ & $66(52-91)$ & $7(2-102)$ \\
\hline SA-HDTMA & $\mathbf{0} \pm \mathbf{0}$ & 0 & - & $14 \pm 14$ & $\mathbf{0}$ & - \\
\hline SA-PTMA $_{50}$ & $455 \pm 12$ & 222 (209-236) & $6(5-9)$ & $304 \pm 69$ & $130(113-153)$ & $15(6-708)$ \\
\hline SA-PTMA 100 & $\mathbf{2 7 6} \pm \mathbf{1 8}$ & $201(176-235)$ & $4(2-8)$ & $\mathbf{1 7 8} \pm \mathbf{1 7}$ & $117(99-141)$ & $6(3-28)$ \\
\hline
\end{tabular}

$\dagger$ The concentration at which $K_{d}$ was determined was $0.4 \mathrm{mmol} \mathrm{L}^{-1}$.

$\ddagger$ The metal concentration range was $0.2-1.5 \mathrm{mmol} \mathrm{L}^{-1}$.

$\S$ Standard error of the coefficients.

II Not determined.

\# Very low or negligible adsorption. 

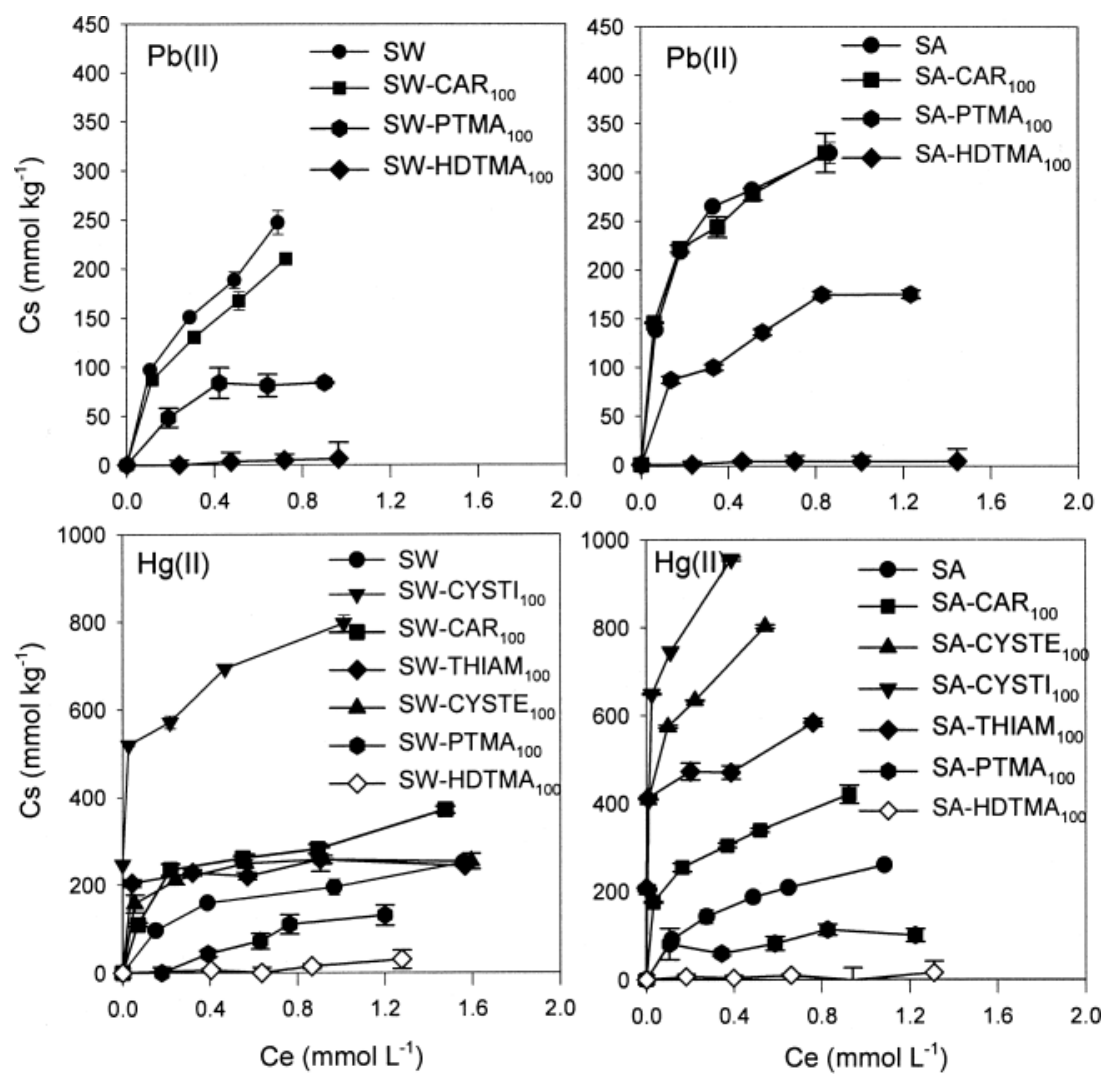

Fig. 2. $\mathrm{Pb}$ (II) and $\mathrm{Hg}$ (II) adsorption isotherms on selected organoclays.

The original SW and SA clays decreased their adsorption capacity when they were exchanged with alkylammonium cations, HDTMA, and PTMA. These cations provide no functionalities with affinity for $\mathrm{Pb}(\mathrm{II})$ but block the exchange sites of the clay mineral. In general, HDTMA, being larger than PTMA, resulted in greater blockage of exchanged sites than PTMA. The residual adsorption in SW-PTMA 100 and SA-PTMA 100 can be due to the heavy metal retention by the edges of the clay. HDTMA cation covered these edges, producing an almost total blockage (Fig. 2).

\section{Hg(II) Adsorption}

The $\mathrm{Hg}(\mathrm{II})$ adsorption isotherms (Fig. 2, Table 2) showed a great increase in the $\mathrm{Hg}$ (II) adsorption after treatment of the clays with the functionalized organic cations, whereas the adsorption capacity of the clays exchanged with alkylammonium cations decreased similar to that observed for $\mathrm{Pb}(\mathrm{II})$. The greatest increase in the $\mathrm{Hg}(\mathrm{II})$ adsorption was observed in the clays exchanged with CYSTI, CYSTE, and THIAM cations, which can be attributed to the high affinity of $\mathrm{Hg}$ (II) for S-containing groups of these cations (Mercier and Detellier, 1995; Mercier and Pinnavaia, 1998; Feng et al., 1997; Celis et al., 2000).

In general, $\mathrm{Hg}$ (II) retention increased with the amount of CYSTE and CYSTI cations, most likely due to the increase in the number of S-containing groups present in the exchanged clays (Mercier and Detellier, 1995; Xia et al., 1999; Celis et al., 2000; Lagadic et al., 2001), which also produced an increase in the separation of the sheets of the clay (Cruz-Guzmán et al., 2004). According to the higher $L$ values for the functionalized organoclays than for the original clays SW and SA, the clays exchanged with functionalized organic cations seem to have higher affinity for $\mathrm{Hg}$ (II) than the pure clays (Table 2) (Celis et al., 2000).

It is important to note how SW-CYSTE and SWTHIAM organoclays exchanged at $50 \%$ of the CEC displayed greater $\mathrm{Hg}$ (II) adsorption than the same organoclays exchanged at $100 \%$ of the CEC (Table 2). Although at low $\mathrm{Hg}$ (II) concentrations SW-CYSTE 100 and SW-THIAM ${ }_{100}$ retained more $\mathrm{Hg}$ (II) than the original clay SW, at high $\mathrm{Hg}$ (II) levels they had a behavior similar to that of SW (Fig. 2). In this regard, Celis et al. (2000) suggested the congestion of the internal porosity of clay minerals as a main obstacle to heavy metal adsorption by functionalized clays.

The clays exchanged with the alkylammonium cations HDTMA and PTMA had less $\mathrm{Hg}(\mathrm{II})$ adsorption capacity than the untreated clay (Fig. 2, Table 2), possibly due to the absence of functional groups with affinity for the metal in these alkylammonium cations and the blockage of the clay exchange sites. In general, HDTMA, with a larger size than PTMA, resulted in greater blockage of adsorption sites for the heavy metal than PTMA, as was observed for Pb(II).

The amount of $\mathrm{Hg}(\mathrm{II})$ retained by the functionalized organoclays was higher than the retained amount of $\mathrm{Pb}$ (II) (Table 2), except in the case of SA-CAR samples, which had similar values of $\mathrm{C}_{\mathrm{m}}$ for $\mathrm{Pb}$ and $\mathrm{Hg}$ (Table 2). It seems that $\mathrm{Hg}(\mathrm{II})$ has an affinity for the $\mathrm{COOH}$ group 
similar to that of $\mathrm{Pb}$ (II), although $\mathrm{Hg}$ (II) has a higher affinity for the sulfur of the organic cations CYSTE, CYSTI, and THIAM. Brown et al. (1999) explained the low affinity of $\mathrm{Pb}$ (II) for - $\mathrm{SH}$ groups of functionalized organoclays by the thermodynamic inability of this metal ion to be coordinated inside the internal porosity of the adsorbents.

Other authors have studied the interaction between $-\mathrm{SH}$ groups and the heavy metals $\mathrm{Pb}$ (II) and $\mathrm{Hg}$ (II). Celis et al. (2000) used a montmorillonite exchanged with 2mercaptoethylammonium cations and observed a greater $\mathrm{Hg}$ (II) adsorption capacity than that of $\mathrm{Pb}$ (II). Lagadic et al. (2001) studied the $\mathrm{Pb}(\mathrm{II}), \mathrm{Hg}(\mathrm{II})$, and $\mathrm{Cd}(\mathrm{II})$ adsorption on a thiol-functionalized layered magnesium phyllosilicate material. The amounts of adsorbed metal decreased in the following order: $\mathrm{Hg}(\mathrm{II})>\mathrm{Pb}(\mathrm{II})>$ $\mathrm{Cd}(\mathrm{II})$. Bois et al. (2003) prepared functionalized silica with amine and mercapto groups for heavy metal ions adsorption. Krishnan and Anirudhan (2002) studied the uptake of heavy metals as $\mathrm{Pb}(\mathrm{II}), \mathrm{Hg}(\mathrm{II}), \mathrm{Cd}(\mathrm{II})$, and $\mathrm{Co}(\mathrm{II})$, in batch systems by sulfurized steam activated carbon, obtaining high-affinity adsorption isotherms in all cases (Giles et al., 1960).

\section{Hg(II) Adsorption at Low Heavy Metal Concentrations}

The behavior of the adsorbents at high $\mathrm{Hg}$ concentrations was confirmed at a lower concentration range by the use of the CVAS technique, according to the method of Bloom and Crecelius (1983). The $\mathrm{Hg}$ (II) adsorption isotherms on SA, SA-CYSTE 100 and SA-CYSTI ${ }_{100}$, at high and low concentration ranges are compared in Fig. 3. The results obtained with CVAS at low $\mathrm{Hg}$ concentrations (Fig. 3a) are consistent with those obtained at higher concentrations measured using Atomic Absorption Spectroscopy (Fig. 3b).

\section{$\mathrm{Pb}$ (II) and $\mathrm{Hg}$ (II) Desorption Studies}

$\mathrm{Pb}(\mathrm{II})$ and $\mathrm{Hg}$ (II) desorption curves, representing the percentage of adsorbed metal versus the number of desorption treatments, for the selected organoclays are shown in Fig. 4 and 5. In all cases, the desorption process was performed using different solutions with $\mathrm{pH}$ 3: 0.001 $M \mathrm{HNO}_{3}, 0.1 M \mathrm{NaNO}_{3}$, and $0.1 M \mathrm{Ca}\left(\mathrm{NO}_{3}\right)_{2}$.

$\mathrm{Pb}(\mathrm{II})$ desorption curves from $\mathrm{SW}, \mathrm{SA}, \mathrm{SW}-\mathrm{CAR}_{100}$, and SA-CAR ${ }_{100}$ samples are shown in Fig. 4. With
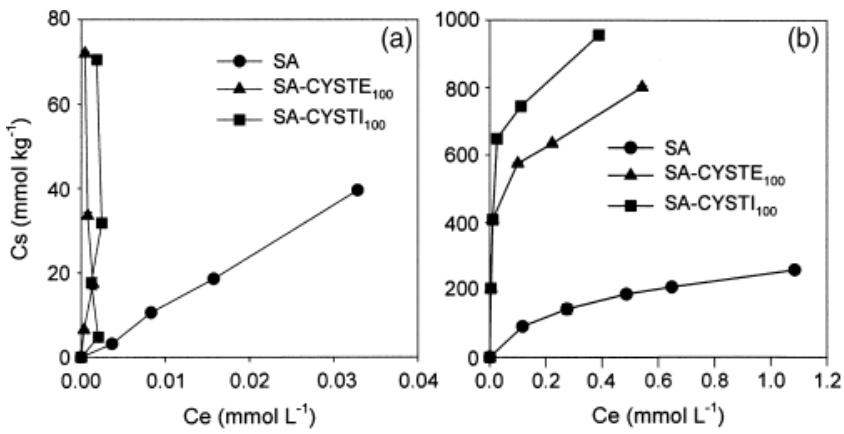

Fig. 3. Hg(II) adsorption isotherms at low (a) and high (b) metal ion concentrations.
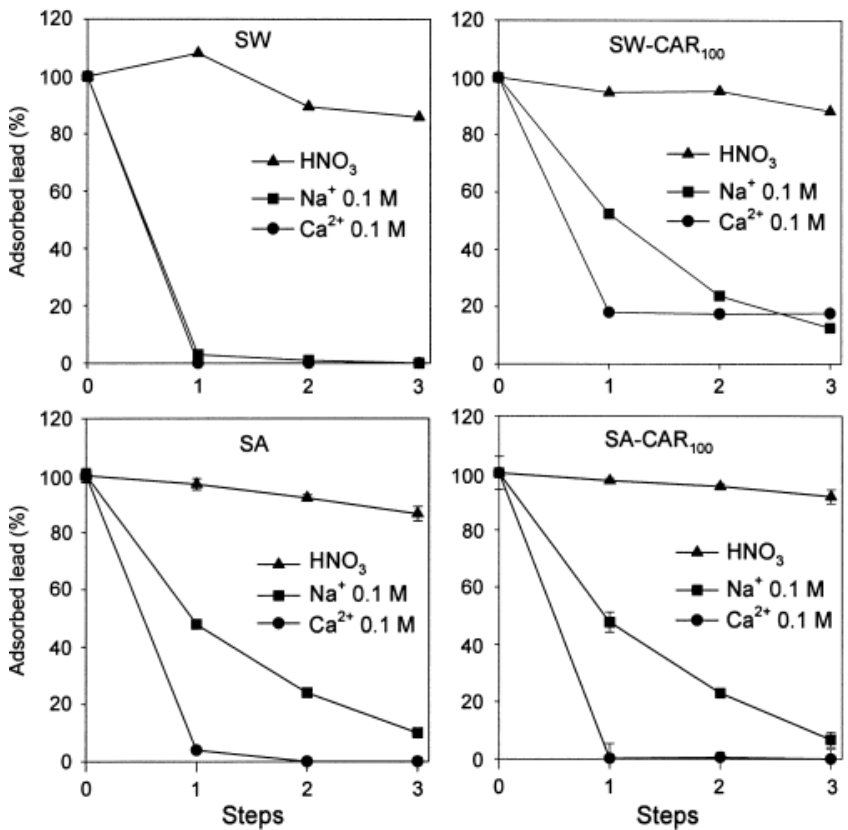

Fig. 4. $\mathrm{Pb}(\mathrm{II})$ desorption from unexchanged and exchanged clays.

similar solutions for the desorption process, we observed a more irreversible $\mathrm{Pb}(\mathrm{II})$ adsorption on SW-CAR than that on SW. It seems that the COOH group of carnitine in SW-CAR ${ }_{100}$ increased the strength of the retention of $\mathrm{Pb}$ (II) as compared with the metal retention on SW. This fact was not observed for SA and SA-CAR ${ }_{100}$ samples, possibly due to the high layer charge of SA, which increased the strength of the $\mathrm{Pb}$ (II) retention on SA. For all adsorbents, the degree of metal desorption increased with the ionic strength of the solution used, following the order $\mathrm{Ca}^{2+}>\mathrm{Na}^{+}>\mathrm{HNO}_{3}$.

Figure 5 shows the $\mathrm{Hg}$ (II) desorption curves from $\mathrm{SW}$, SA, SW-CYSTI ${ }_{100}$, SW-THIAM 100, SA-CYSTI $_{100}$, and SA-THIAM ${ }_{100}$ samples. The $\mathrm{Hg}($ II) adsorption irreversibility followed the order SW $<$ SW-CYSTI $<$ SWTHIAM. Irreversibility was observed in the $\mathrm{Hg}$ (II) adsorption on SW-THIAM ${ }_{100}$ with the use of solutions of low ionic strength $\left(\mathrm{HNO}_{3}\right.$ or $\left.\mathrm{Na}^{+}\right)$. Although the $\mathrm{Hg}(\mathrm{II})$ retention by $\mathrm{SW}_{-\mathrm{CYSTI}}{ }_{100}$ was greater than that by SW-THIAM ${ }_{100}$ (Fig. 2), it seems that the metal retention strength was higher for SW-THIAM ${ }_{100}$ than for SW-CYSTI ${ }_{100}$.

For SA-CYSTI ${ }_{100}$ and SA-THIAM ${ }_{100}$ organoclays, the desorption process was practically negligible, even using $\mathrm{Na}^{+}$and $\mathrm{Ca}^{2+}$ solutions. In contrast, desorption was reversible for the original clay SA.

\section{CONCLUSIONS}

The results of this work show that the presence of functional groups in the organic cation influences the adsorption capacity and selectivity of organoclays for heavy metals. Consequently, a suitable selection of the chemical characteristics of the organic cation can optimize the adsorbent properties of the organoclays as compared with the use of alkylammonium cations, which lack heavy 

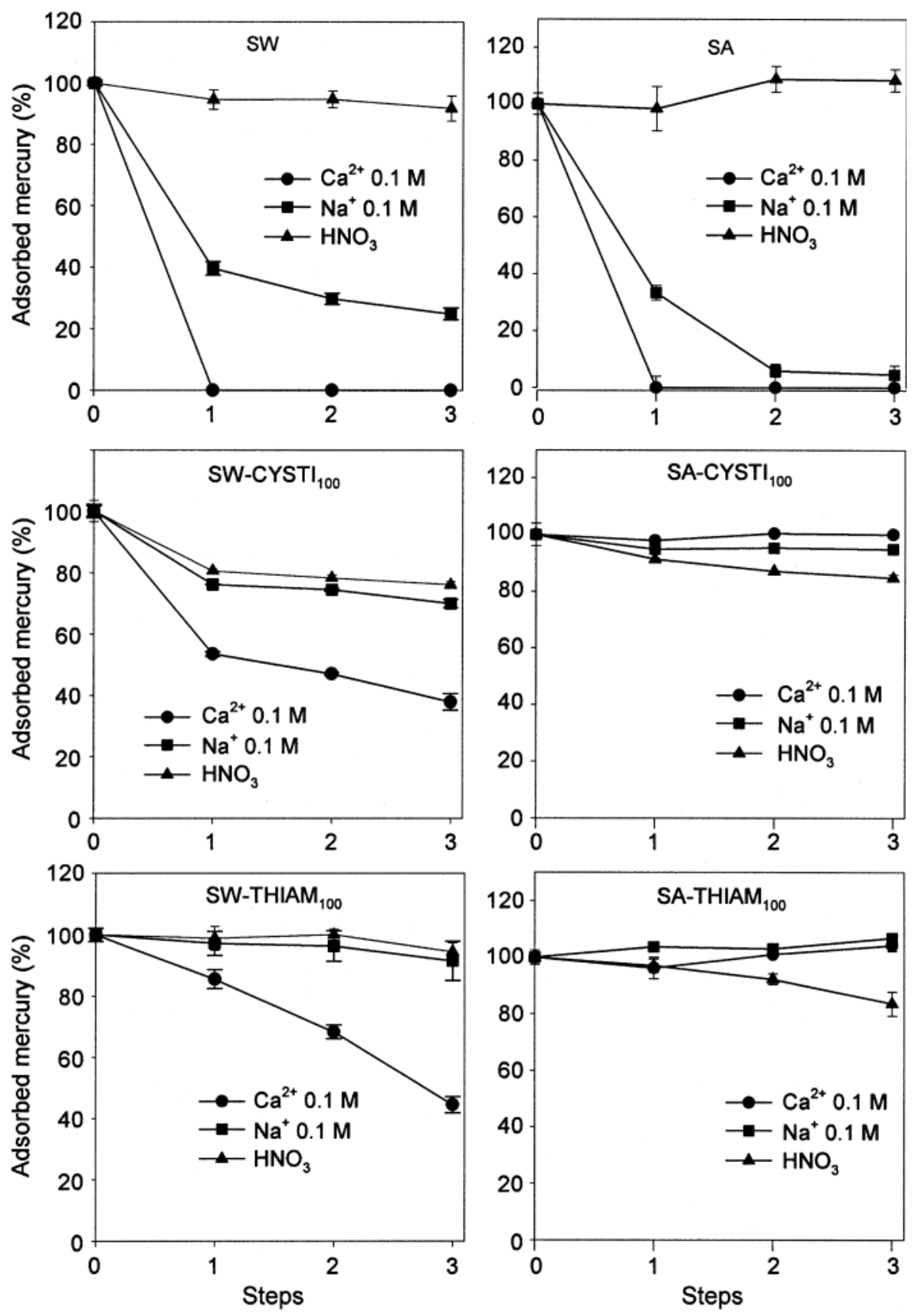

Fig. 5. Hg(II) desorption from unexchanged and exchanged clays.

metal adsorption capacity. In general, organoclays with high affinity for $\mathrm{Pb}$ (II) and $\mathrm{Hg}$ (II) showed a greater resistance to desorption as compared with organoclays with a lower affinity for heavy metals. These results reveal that functionalized organoclays could be useful as agents to selectively remove heavy metals from contaminated water. On the basis of previous work showing the usefulness of organoclays for adsorbing organic pollutants, functionalized organoclays could find application for the treatment of water contaminated with heavy metals and organic pollutants. The viability of using natural functionalized organic cations to prepare organoclays is interesting for minimizing the impact of the adsorbent once introduced into the environment.

\section{ACKNOWLEDGMENTS}

This work was partially supported by the MCYT Project REN2001-1700-CO2-01/TECNO and by Junta de Andalucía through Research Group RNM124. M.C-G. gratefully acknowledges the Spanish Ministry of Education and Culture for her F.P.U. fellowship.

\section{REFERENCES}

Andrades, M.S., M.S. Rodríguez-Cruz, M.J. Sánchez-Martín, and M. Sánchez-Camazano. 2004. Effect of the modification of natural clay minerals with hexadecylpyridinium cation on the adsorptiondesorption of fungicides. Intern. J. Environ. Anal. Chem. 84: 133-141.

Bloom, N.S., and E.A. Crecelius. 1983. Determination of mercury in seawater at sub-nanogram per liter levels. Mar. Chem. 14:49-89. 
Bois, L., A. Bonhomme, A. Ribes, B. Pais, G. Raffin, and F. Tessier. 2003. Functionalized silica for heavy metal ions adsorption. Colloids Surf. A, Physicochem. Eng. Asp. 221:221-230.

Brigatti, M.F., G. Campana, L. Medici, and L. Poppi. 1996. The influence of layer-charge on $\mathrm{Zn}^{2+}$ and $\mathrm{Pb}^{2+}$ sorption by smectites. Clays Clay Min. 31:477-483.

Brown, J., L. Mercier, and T.J. Pinnavaia. 1999. Selective adsorption of $\mathrm{Hg}^{2+}$ by thiol-functionalized nanoporous silica. Chem. Commun. 1: 69-70.

Carrizosa, M.J., W.C. Koskinen, M.C. Hermosín, and J. Cornejo. 2001. Dicamba adsorption-desorption on organoclays. Appl. Clay Sci. 18: 223-231.

Celis, R., W.C. Koskinen, A.M. Cecchi, G.A. Bresnahan, M.J. Carrizosa, M.A. Ulibarri, I. Pavlovic, and M.C. Hermosín. 1999. Sorption of the ionizable pesticide imazamox by organoclays and organohydrotalcites. J. Environ. Sci. Health B 34:929-941.

Celis, R., M.C. Hermosín, and J. Cornejo. 2000. Heavy metal adsorption by functionalized clays. Environ. Sci. Technol. 34:4593-4599.

Celis, R., M.C. Hermosín, M.J. Carrizosa, and J. Cornejo. 2002. Inorganic and organic clays as carriers for controlled release of the herbicide hexazinone. J. Agric. Food Chem. 50:2324-2330.

Cruz-Guzmán, M., R. Celis, M.C. Hermosín, and J. Cornejo. 2004. Adsorption of the herbicide simazine by montmorillonite modified with natural organic cations. Environ. Sci. Technol. 38:180-186.

Cruz-Guzmán, M., R. Celis, M.C. Hermosín, W.C. Koskinen, and J. Cornejo. 2005. Adsorption of pesticides from water by functionalized organobentonites. J. Agr. Food Chem. 53:7502-7511.

Evanko, C.R., and D.A. Dzombak. Remediation of metals-contaminated soil and groundwater. GWRTAC. Available at ww.gwrtac.org (accessed 1 April 2005; verified17 October 2005).

Feng, X., G.E. Fryxell, L.Q. Wang, A.Y. Kim, J. Liu, and K.M. Kemner. 1997. Functionalized monolayers on ordered mesoporous supports. Science 276:923-926.

Giles, C.H., T.H. MacEwan, S.N. Nakhawa, and D. Smith. 1960. Studies in adsorption. Part XI. A system of classification of solution adsorption isotherms, and its use in diagnosis of adsorption mechanisms and in measurement of specific surface areas of solids. J. Chem. Soc. London 3:3973-3993.

Gu, B., J. Schmitt, Z. Chen, L. Liang, and J.F. McCarthy. 1995. Adsorption and desorption of different organic matter fractions on iron oxide. Geochim. Cosmochim. Acta 59:219-229.
Hermosín, M.C., and J. Cornejo. 1992. Removing 2,4-D from water by organo-clays. Chemosphere 24:1493-1503.

Krishnan, K.A., and T.S. Anirudhan. 2002. Uptake of heavy metals in batch systems by sulfurized steam activated carbon prepared from sugarcane bagasse pith. Ind. Eng. Chem. Res. 41:5085-5093.

Lagadic, I.L., M.K. Mitchell, and B.D. Payne. 2001. Highly effective adsorption of heavy metal ions by a thiol-functionalized magnesium phyllosilicate clay. Environ. Sci. Technol. 35:984-990.

Lee, J.J., J. Choi, and J.W. Park. 2002. Simultaneous sorption of lead and chlorobenzene by organobentonite. Chemosphere 49:1309-1315.

Mercier, L., and C. Detellier. 1995. Preparation, characterization and applications as heavy metals sorbents of covalently grafted thiol functionalities on the interlamellar surface of montmorillonite. Environ. Sci. Technol. 29:1318-1323.

Mercier, L., and T.J. Pinnavaia. 1998. Heavy metal ion adsorbents formed by the grafting of thiol functionality to mesoporous silica molecular sieves: Factors affecting $\mathrm{Hg}^{2+}$ uptake. Environ. Sci. Technol. 32:2749-2754.

Sheng, G., S.H. Xu, and S.A. Boyd. 1999. A dual function organoclay sorbent for lead and chlorobenzene. Soil Sci. Soc. Am. J. 63:73-78.

Siantar, D.P., B.A. Feinberg, and J.J. Fripiat. 1994. Interaction between organic and inorganic pollulants in the clay interlayer. Clays Clay Min. 42:187-196.

Stadler, M., and P.W. Schindler. 1993. The effect of dissolved ligands upon the sorption of $\mathrm{Cu}(\mathrm{II})$ by $\mathrm{Ca}-\mathrm{montmorillonite.} \mathrm{Clays} \mathrm{Clay}$ Min. 41:680-692.

Staunton, S., and M. Roubaud. 1997. Adsorption of Cs-137 on montmorillonite and illite: Effect of charge compensation cation, ionic strength, concentration of $\mathrm{Cs}, \mathrm{K}$ and fulvic acid. Clays Clay Min. 45:251-260.

Tiller, K.G. 1989. Heavy metals in soils and their environmental significance. Adv. Soil Sci. 9:113-142.

Tofan, L., and C. Paduraru. 2004. Sorption studies of $\mathrm{Ag}(\mathrm{I}), \mathrm{Cd}(\mathrm{II})$ and $\mathrm{Pb}$ (II) ions. Croat. Chem. Acta 77:581-586.

Undabeytia, T., E. Morillo, and C. Maqueda. 1996. Adsorption of Cd and $\mathrm{Zn}$ on montmorillonite in the presence of a cationic pesticide. Clays Clay Min. 31:485-490.

Xia, K., U.L. Skyllberg, W.F. Bleam, P.R. Bloom, E.A. Nater, and P.A. Helmke. 1999. X-ray absorption spectroscopic evidence for the complexation of $\mathrm{Hg}(\mathrm{II})$ by reduced sulfur in soil humic substances. Environ. Sci. Technol. 33:257-261. 